(c) American Dairy Science Association, 2007.

\title{
Evidence for Fibril-Like Structure in Bovine Casein Micelles
}

\author{
R. W. Lencki \\ Department of Food Science, University of Guelph, Guelph, Ontario, Canada N1G 2W1
}

\begin{abstract}
The addition of Congo red (CR) dye to diluted raw skim milk resulted in a red shift indicative of the presence of fibril-like structures. Thioflavin $\mathrm{T}(\mathrm{ThT})$ is another dye that very specifically binds to protein fibrils, and when added to undiluted raw skim milk, the classic $485 \mathrm{~nm}$ fluorescence peak of a ThT-fibril complex was observed. Repeating these experiments with various raw milk components showed that the $\mathrm{CR}$ red shift and ThT fluorescence peak were due to the presence of casein micelles, and to a lesser extent, sodium caseinate. Fluorescent peaks were also observed when ThT was added to solutions of purified $\alpha_{\mathrm{S}^{-}}$and $\kappa$-casein, but not $\beta$-casein, in 0.5 $M$ HEPES buffer $(\mathrm{pH}=$ 6.8). The addition of $25 \mathrm{mM} \mathrm{Ca}{ }^{2+}$ had no effect on $\beta$ casein fluorescence, and significantly reduced the $\kappa$ casein peak. However, adding $25 \mathrm{mM} \mathrm{Ca}{ }^{2+}$ to $\alpha_{\mathrm{S}}$-casein produced a turbid solution and a 6 -fold increase in fluorescence, indicating that the aggregates formed contain fibril-like structure. Casein micelle images obtained by transmission electron microscopy showed the presence of short ( 7 to $10 \mathrm{~nm}$ ) fibers cross-linked by dense aggregate junction zones. The observed fibers closely resemble protofibrils, intermediate structures that are observed during the formation of amyloid fibrils.
\end{abstract}

Key words: casein micelle, Congo red, thioflavin T, protofibril

\section{INTRODUCTION}

Bovine casein micelles have an average diameter of approximately $150 \mathrm{~nm}$ and contain 4 principal proteins: $\alpha_{\mathrm{S1}^{-}}, \alpha_{\mathrm{S} 2^{-}}, \beta$-, and $\kappa$-casein (de Kruif and Holt, 2003). Optical rotational dispersion studies initially showed a lack of $\alpha$-helix structure (Farrell, 1988) so it was first believed that caseins were random-coil proteins. This conclusion was further supported by the fact that none of the caseins display a denaturation endotherm at elevated temperature (Paulsson and

Received June 21, 2006.

Accepted August 10, 2006.

E-mail: rlencki@uoguelph.ca
Dejmek, 1990). However, more recent circular dichroism and Raman studies have shown that caseins likely possess a significant amount of secondary structure (Swaisgood, 2003).

The exact mechanism by which the various caseins interact to form micelles has also been a subject of much study and debate. Rollema (1992) suggested that micelles consist of substructures held together by both hydrophobic bonds and colloidal calcium phosphate (CCP) ion bridges. Early scanning electron microscopy studies seemed to indicate the presence of submicelles, but McMahon and McManus (1998) have shown that these structures were likely artifacts of the fixation process. Holt (1992) has argued that the evidence for substructures is weak and that the micelle is simply a tangled network of polypeptide chains cross-linked by CCP. Most models have suggested that $\kappa$-casein concentrates on the colloid surface, creating a stabilizing hairy layer that, when disrupted, leads to protein aggregation (Griffin and Roberts, 1985).

A particular class of proteins-described as nonregular-has recently received a great deal of attention because of their tendency to self-assemble into fibrillar protein deposits (Rochet and Lansbury, 2000). With these proteins, aggregation is not random but involves the formation of ordered fibrils made up of polypeptide chains in a $\beta$-conformation that are hydrogen-bonded together into sheets running parallel to the fiber axis (Sunde and Blake, 1997). Destabilizing amino acid mutations of normally stable globular proteins can also create amylogenic structures, leading to disorders such as hereditary systemic amyloidosis (Kelly, 1996). In addition, many globular proteins such as $\beta$-LG that are not normally amyloidogenic in vivo have been shown to undergo fibrillar self-assembly under partially denatured conditions (Carrotta et al., 2001).

Despite considerable research, the exact nature of these fibril structures remains unclear (Nelson and Eisenberg, 2006). The core structure appears to be stabilized primarily by hydrogen bonding of the main polypeptide chain so it is much less protein-specific than the highly individualistic globular structures of native globular proteins (Dobson, 2003). With natively disordered proteins, all or part of the peptide first folds into a 5 - to 13 -nm wide parallel $\beta$-sheet structure with H-bonds along the fibril axis (Benzinger et al., 1998). 
Fibril formation begins with proteins associating into small bead-like amorphous aggregates that transform into short, thin protofibrils (Dobson, 2003). These structures are formed when $\beta$-pleated sheets laminate through side-chain interactions to create a helical structure, with 24 sheets required to complete a helical turn about an axis parallel to the fiber axis (Fink, 1998). These structures can then assemble into long strands, several of which can then intertwine to form a linear unbranched fibril having a length of 200 to $600 \mathrm{~nm}$.

The classic means of detecting fibril structures is through Congo red (CR) staining. The 2 sulfonic acid groups of Congo red specifically bind to 2 positively charged amino acid residues on 2 separate protein molecules that are properly oriented in the $\beta$-pleated sheet conformation in the protofibril laminate structure (Klunk et al., 1989). This results in a spectral shift that can be used to quantify profibril concentration (Klunk et al., 1999). Thioflavin T (ThT) is a positively charged dye that is also used to detect the presence of fibril structures (LeVine, 1999). When excited at 442 $\mathrm{nm}$, the fibril-ThT complex will display a fluorescent peak at $485 \mathrm{~nm}$. Although it is considered to be more specific than CR with regard to fibril detection, the exact nature of the ThT binding mechanism and the fibril structures to which it binds is still under investigation (Khurana et al., 2005).

Recently, Thorn et al. (2005) used ThT binding experiments to show that $\alpha_{\mathrm{S}^{-}}$and $\kappa$-caseins can form fibril structures, and also play a preventative role in amyloid deposition in mammary tissue (corpora amylacea). The fact that caseins are natively disordered or rheomorphic (Holt and Sawyer, 1993) and are capable of forming ordered aggregates leads to the hypothesis that fibril structures could also be present in native micelles.

\section{MATERIALS AND METHODS}

\section{Chemicals and Proteins}

Reagent-grade HEPES and Congo red were obtained from Fisher Scientific (Nepean, Ontario, Canada); mercaptoethanol and thioflavin $\mathrm{T}$ were purchased from Aldrich Chemical (Mississauga, Ontario, Canada).

Simulated milk ultrafiltrate (SMUF) was prepared using the methodology of Jenness and Koops (1962) from reagent grade chemicals obtained from Fisher Scientific. $\alpha_{\mathrm{S}^{-}}, \beta$-, and $\kappa$-casein, BSA, $\alpha$-LA, and $\beta$-LG were purchased from Sigma Chemical (Mississauga, Ontario, Canada) and used without further purification.

\section{Skim Milk, Casein Micelle, and Sodium Caseinate Preparation}

Raw milk was analyzed within a few hours of its procurement from a local farm. Centrifugation at 1,400 $\times g$ for 20 min was performed at $5^{\circ} \mathrm{C}$ with an ICN model HN-SII centrifuge (Thermo Electron, Waltham, MA) to remove fat globules. Casein micelles were then removed from the raw skim milk by centrifuging the sample at $23^{\circ} \mathrm{C}$ for $45 \mathrm{~min}$ at $43,000 \times g$ with an Optima LE-8K ultracentrifuge (Beckman Coulter, Fullerton, CA). After removing the whey supernatant, the casein micelle pellet was then washed with SMUF at room temperature, ultracentrifuged again, and then resuspended in the appropriate aqueous solution.

Caseinate was prepared by acidification of raw skim milk with $1.0 \mathrm{~N} \mathrm{HCl}$ to $\mathrm{pH} 4.6$ at $5^{\circ} \mathrm{C}$. After holding for $30 \mathrm{~min}$, the temperature was increased to $23^{\circ} \mathrm{C}$ and the coagulated milk was centrifuged at $1,400 \times g$ for 20 min with an ICN model HN-SII centrifuge. The solid coagulum was washed 3 times with deionized water, suspended in 5 times the solid volume of deionized water, and the $\mathrm{pH}$ was then adjusted to 6.8 with $1.0 \mathrm{~N} \mathrm{NaOH}$. Stirring was applied until the protein was completely dissolved.

\section{SDS-PAGE}

Sodium dodecyl sulfate-PAGE was used to verify the composition and purity of the casein preparations. Separation was performed on a Phastsystem using a $20 \%$ homogeneous Phasgel (Amersham, Baie d'Urfé, Quebec, Canada). Reagent concentrations were those suggested by the manufacturer. Scanned gels were analyzed using Image J software (http://rsb.info.nih.gov/ij).

\section{Congo Red Absorbance Spectroscopy}

Absorbance spectra between 450 and $625 \mathrm{~nm}$ for solutions containing HEPES buffer, skim milk, micelles, whey, $\alpha_{\mathrm{S}^{-}}, \beta$-, and $\kappa$-casein (with or without 15 $\mu M$ CR were determined at $23^{\circ} \mathrm{C}$ using an HP 8452A Spectrophotometer (Agilent, Mississauga, Ontario, Canada).

\section{Thioflavin T Fluorescent Spectroscopy}

Fluorescence spectra were determined at $23^{\circ} \mathrm{C}$ for solutions with or without $5 \mu M$ ThT addition using a RF-5301PC Spectrofluorophotometer (Shimadzu, Tokyo, Japan). Solutions not containing ThT were used as blanks. 


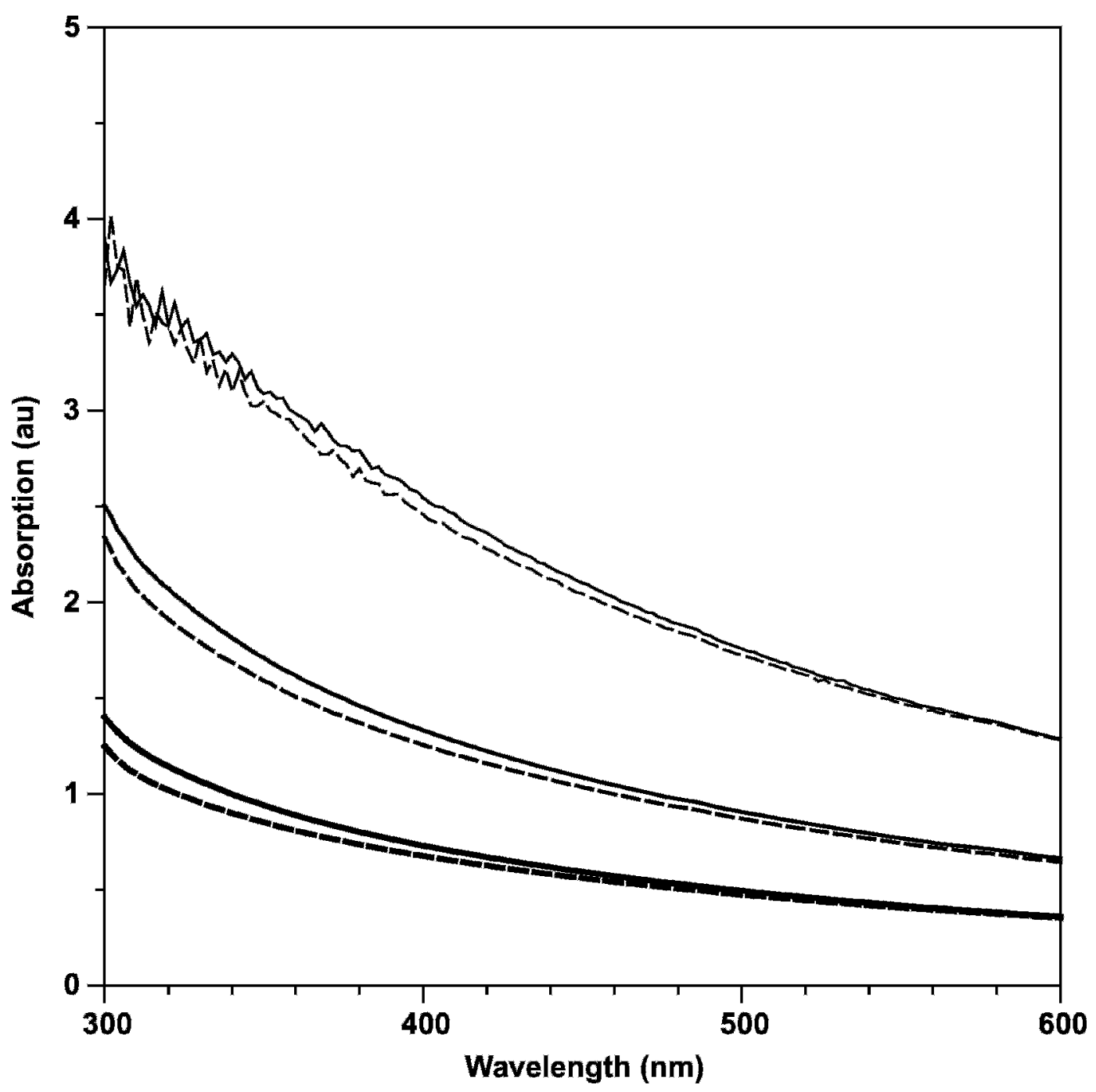

Figure 1. Baseline absorbance (arbitrary units) of diluted raw skim milk: $-25 \times ;-50 \times ;-75 \times$. Diluent: solid curves $=$ simulated milk ultrafiltrate, dashed curves = deionized water.

\section{Transmission Electron Microscopy}

Samples were diluted to the appropriate concentration with SMUF and then placed on a Formvar-coated copper grid (SPI, West Chester, PA). After wicking off the excess moisture with filter paper, a phosphotungstic acid stain $(\mathrm{pH}=6.8)$ was applied, and after $30 \mathrm{~s}$ was once again wicked off. Air-dried images were taken using a Hitachi H7100 transmission electron microscope (Hitachi, Mississauga, Ontario, Canada) with an accelerating voltage of $75 \mathrm{kV}$. Focusing was performed away from the structure of interest to minimize drying and molecular damage caused by the electron beam. Digital images were captured using Analysis Pro 3.0 (Soft Image, Montreal, QC). Cryo-transmission electron microscopy (TEM) images were obtained by quenching the grid containing the stained sample in liquid ethane and then transferring it to liquid nitrogen (Bellare et al., 1988). The vitrified samples were placed into a LEO 912AB Omega TEM (Carl Zeiss, Thornwood, NY). Images were taken at an accelerating voltage of $100 \mathrm{kV}$ and analyzed using ESI Vision software (ESI, Portland OR).

\section{RESULTS}

\section{Detection in Raw Skim Milk}

Observing small spectral shifts using absorption spectroscopy in opaque solutions such as raw skim milk is a challenge because of the high degree of scattering present in these samples. Diluting the sample reduces scattering phenomena but this also reduces the amount of protein that can interact with $\mathrm{CR}$, in 


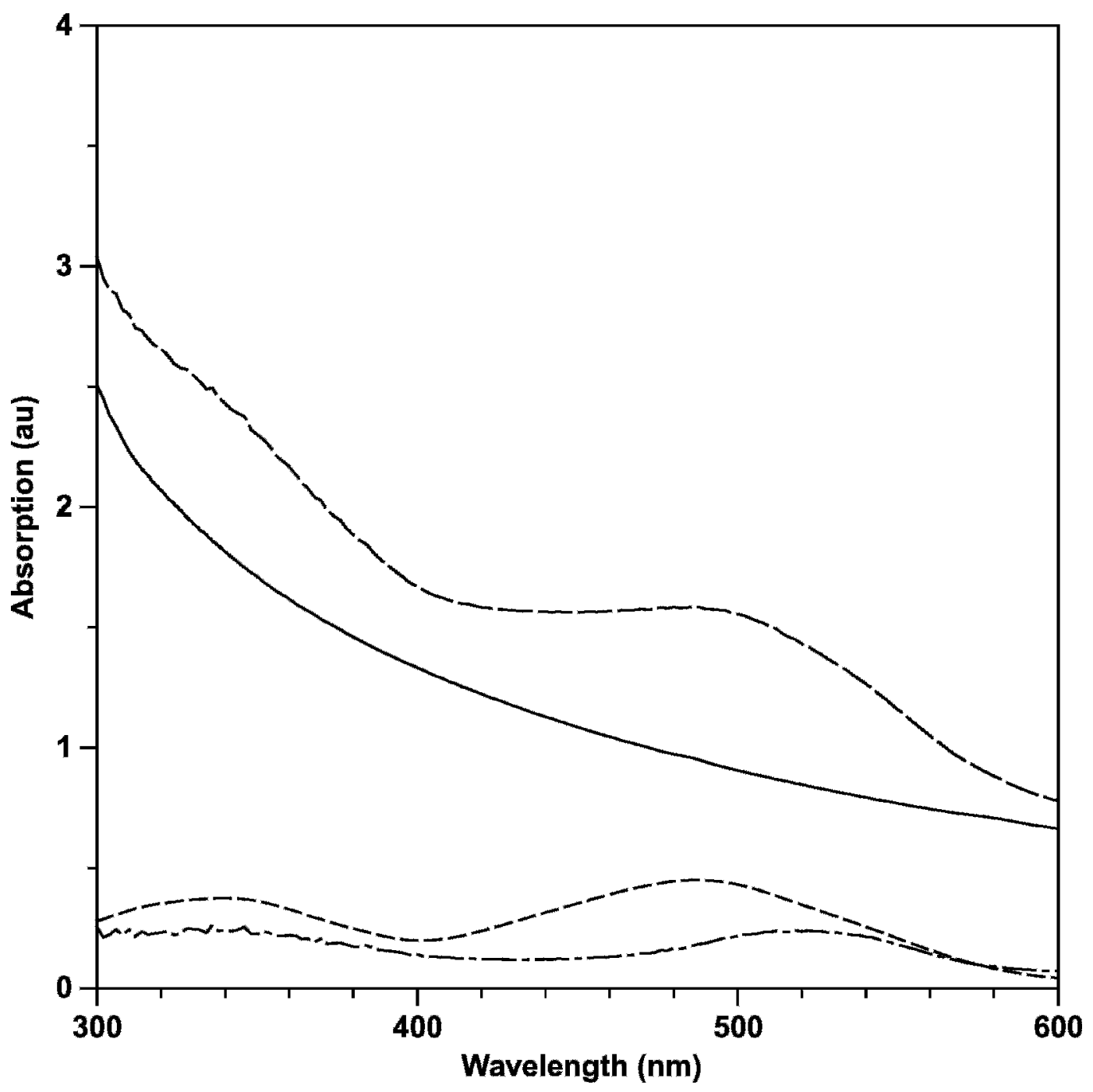

Figure 2. Absorption spectrum (arbitrary units) for raw skim milk diluted 50x: —— raw milk + simulated milk ultrafiltrate $($ SMUF); $---=$ Congo red + SMUF; $--=$ raw milk + Congo red + SMUF; $---=$ difference curve.

turn reducing the size of the spectral shift peak. Thus, an optimal dilution level must be found that balances these 2 effects.

Figure 1 demonstrates the effect of diluting raw skim milk with SMUF and deionized water. At 25× dilution, the baseline is high, uneven, and skewed because lower wavelengths tend to scatter more. At this level of dilution, absorption shifts are difficult to detect because the difference curve is calculated from small differences between large numbers. Higher dilutions of $50 \times$ and $75 \times$ resulted in smoother curves with less skew. The ionic strength of the diluting medium did not have a strong effect on Rayleigh scattering because the baselines for SMUF and deionized water were similar (Figure 1). This is not unexpected because Boulet et al. (1970) have previously demonstrated that dilu- tion with distilled water has little effect on casein micelle structure.

Concentrations of CR between 10 and $15 \mu M$ are suggested for optimum detection of fibril structures (Klunk et al., 1999). Figure 2 shows the resulting absorption spectrum at $23^{\circ} \mathrm{C}$ when $10 \mu M$ CR was added to skim milk diluted $50 \times$ with SMUF to maintain constant ionic concentration. A difference spectrum was generated by subtracting from this scan the spectra from diluted skim milk SMUF solution without CR, and CR dissolved in SMUF (Figure 2). A peak at 541 $\mathrm{nm}$ indicative of $\mathrm{CR}$ fibril protein interactions was obtained (Figure 3). If casein micelles were removed from the raw skim milk by ultracentrifugation, the resulting whey supernatant, when diluted $50 \times$ with SMUF, gave a much smaller difference peak (Figure 


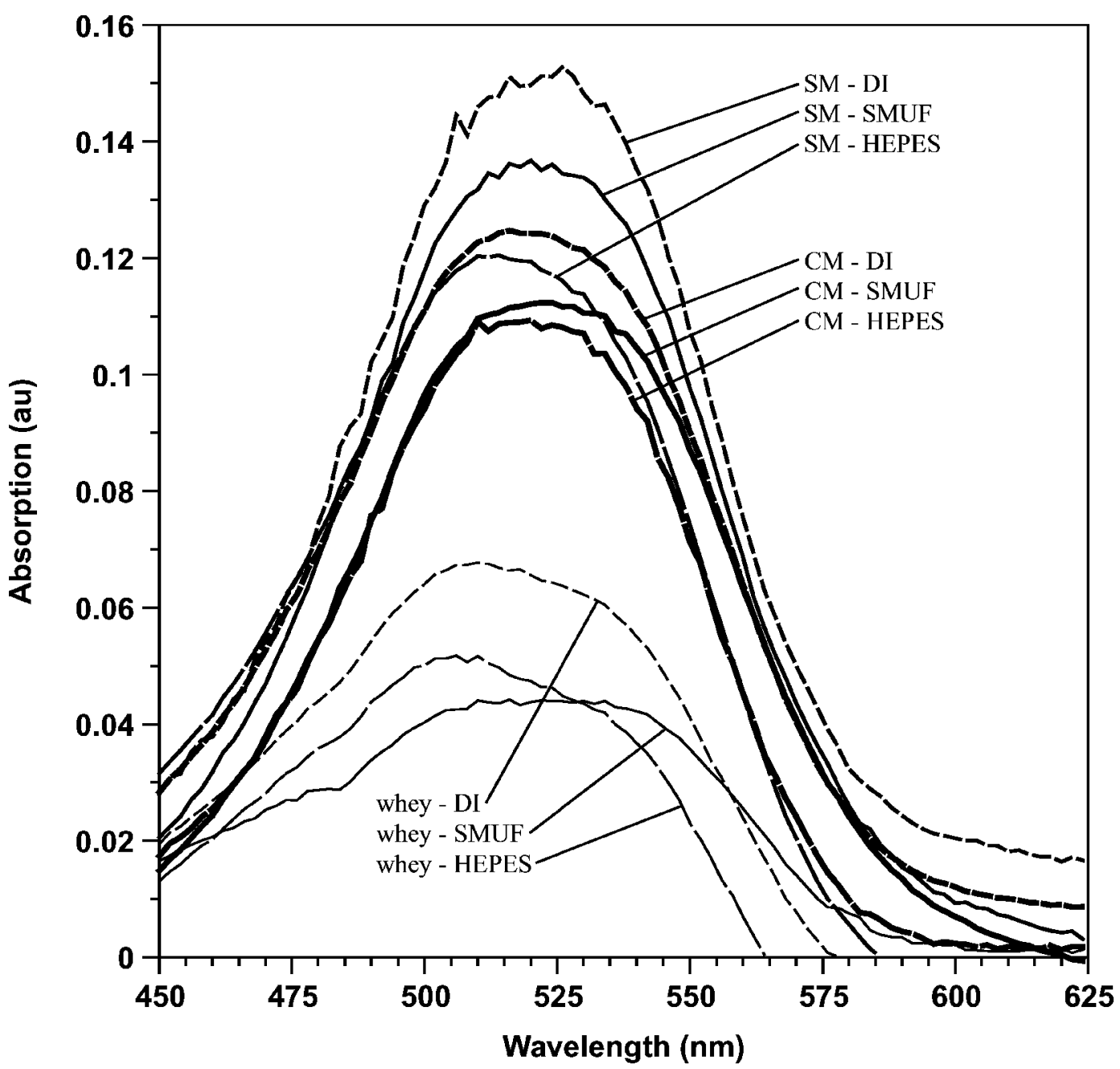

Figure 3. Congo red difference spectra for $50 \times$ dilution: $-=$ skim milk $(\mathrm{SM}) ;-=$ whey; - casein micelles $(\mathrm{CM})$. Diluents: solid curve = simulated milk ultrafiltrate (SMUF); short dashed curve = deionized water $(\mathrm{DI})$; long dashed curve $=0.05 M$ HEPES $(\mathrm{pH}=6.8)$.

3). If the casein pellet produced by ultracentrifugation was then washed with SMUF at room temperature, ultracentrifuged again, resuspended, and then diluted $50 \times$ with SMUF, a difference peak similar to that detected with skim milk was observed (Figure 3 ). Therefore, casein micelles appear to be causing the CR spectral shift. Peaks of similar magnitude were obtained when deionized water or $0.1 M$ HEPES buffer $(\mathrm{pH}=$ 6.8) was used as the dilutent (Figure 3). Even though $\mathrm{CR}$ is negatively charged, the ionic make-up of the surrounding solution did not appear to strongly alter micelle-dye interaction behavior.

Fluorescent probes are generally more sensitive than those used in absorption spectroscopy. Furthermore, because emitted light is detected at a fixed wavelength at right angles to the excitation radiation, fluorescent spectroscopic analysis is less affected by turbid media (Li et al., 1998). Figure 4 shows the emission spectra for undiluted raw skim milk in a $0.1 \times 1.0 \mathrm{~cm}$ quartz cuvette with the length parallel to the excitation beam. The very large peak that appears at the same wavelength as the excitation beam $(442 \mathrm{~nm})$ is due to Rayleigh scattering from water and Tyndall scattering from the colloidal particles present in the skim milk, whereas the broader peak at $520 \mathrm{~nm}$ is due to Raman scattering (Price et al., 1962). When the suggested concentration of $5 \mu M$ ThT was added to raw skim milk with minimal dilution (LeVine, 1999) and the solution was excited at $442 \mathrm{~nm}$, a second peak appeared with a maximum at $485 \mathrm{~nm}$. This peak is particularly evident when a difference curve is calculated by subtracting the raw skim milk spectrum from that of the sample containing ThT. This $485 \mathrm{~nm}$ difference peak is very similar in shape to those previously 


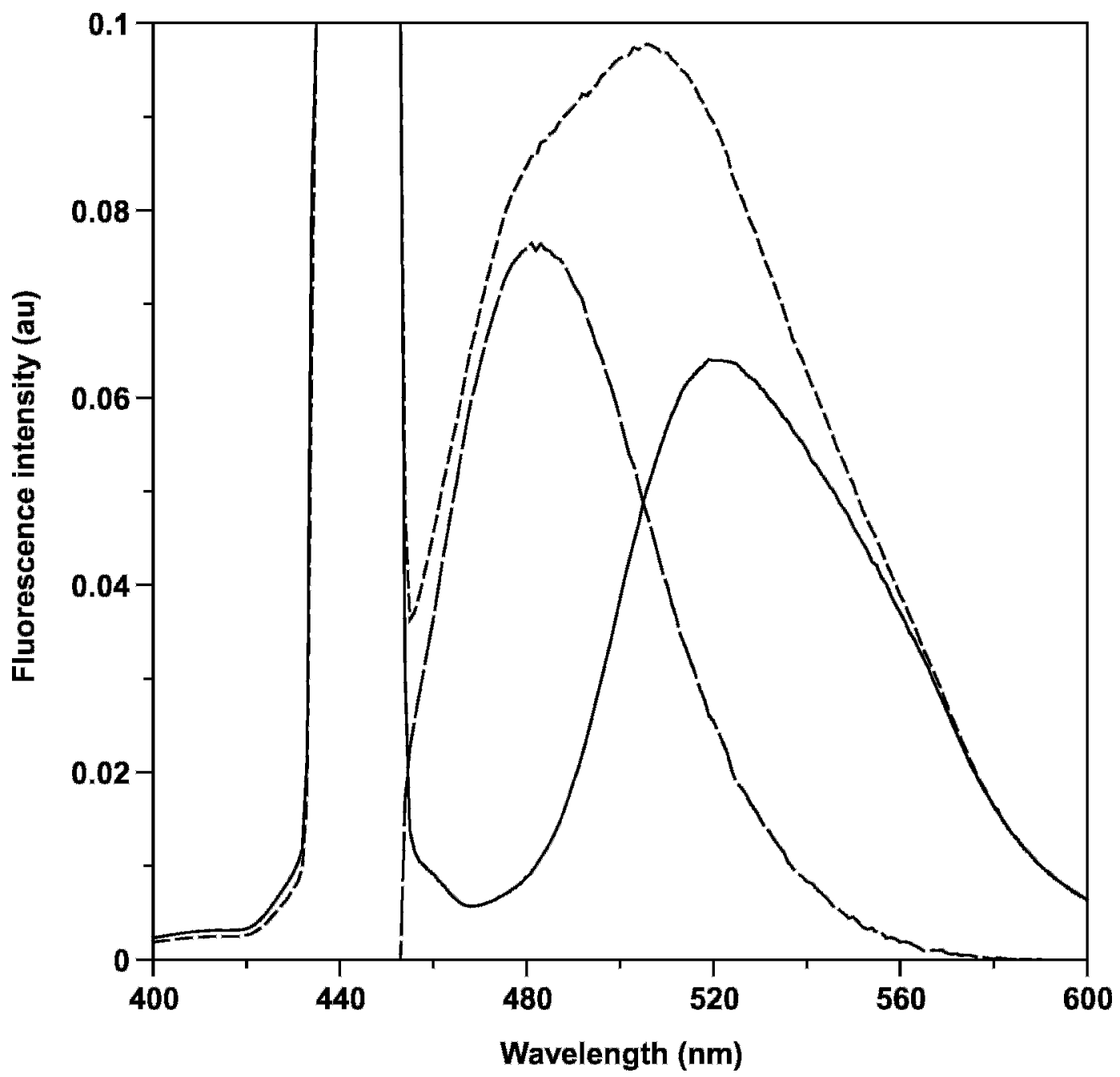

Figure 4. Thioflavin $\mathrm{T}(\mathrm{ThT})$ fluorescence spectra (arbitrary units) for undiluted raw skim milk in a $0.1 \mathrm{~cm} \times 1.0 \mathrm{~cm}$ cuvette: $-=$ raw milk; - - - - = raw milk + ThT; - - = difference curve.

observed for other fibril-ThT complexes (Carrotta et al., 2001).

Greater contrast between the Raman and $485 \mathrm{~nm}$ fibril-ThT complex peak-and thus higher sensitivitycan be obtained by diluting the raw skim milk sample and using a $1.0-\mathrm{cm}$ square quartz cuvette. Figure 5 shows results obtained with raw skim milk diluted $15 \times$ with SMUF. In this case, the Raman peak at 520 $\mathrm{nm}$ is greatly reduced, whereas the $485 \mathrm{~nm}$ peak is of a magnitude similar to that observed in Figure 4.

Figure 6 examines the effect of dilution and diluting media on the $485 \mathrm{~nm}$ fibril-ThT complex peak. The 485 $\mathrm{nm}$ peak height declined in an approximately linear manner as raw skim milk was diluted 20, 25, and 30× with all 3 diluents. However, the ionic composition of the diluent did have a significant influence on fluorescence intensity. Larger peaks were observed when di- luting with deionized water compared with those obtained with SMUF or 0.1 $M$ HEPES buffer $(\mathrm{pH}=6.8)$. Low ionic strength can alter both protein structure and ThT binding affinity, because this dye is positively charged. Dilution with HEPES buffer decreased fluorescence intensity more than SMUF, possibly indicating that not only ionic strength, but also the presence of calcium ion plays a role in fibril structural stability and dye binding.

When the casein micelles were removed from the raw skim milk by ultracentrifugation, the resulting whey supernatant, after $20 \times$ dilutions with SMUF and ThT addition, did not demonstrate any significant fluorescence (Figure 7). If the casein pellet produced by ultracentrifugation was then washed with SMUF at room temperature, ultracentrifuged again, resuspended, and then diluted $20 \times$ with SMUF, after ThT 


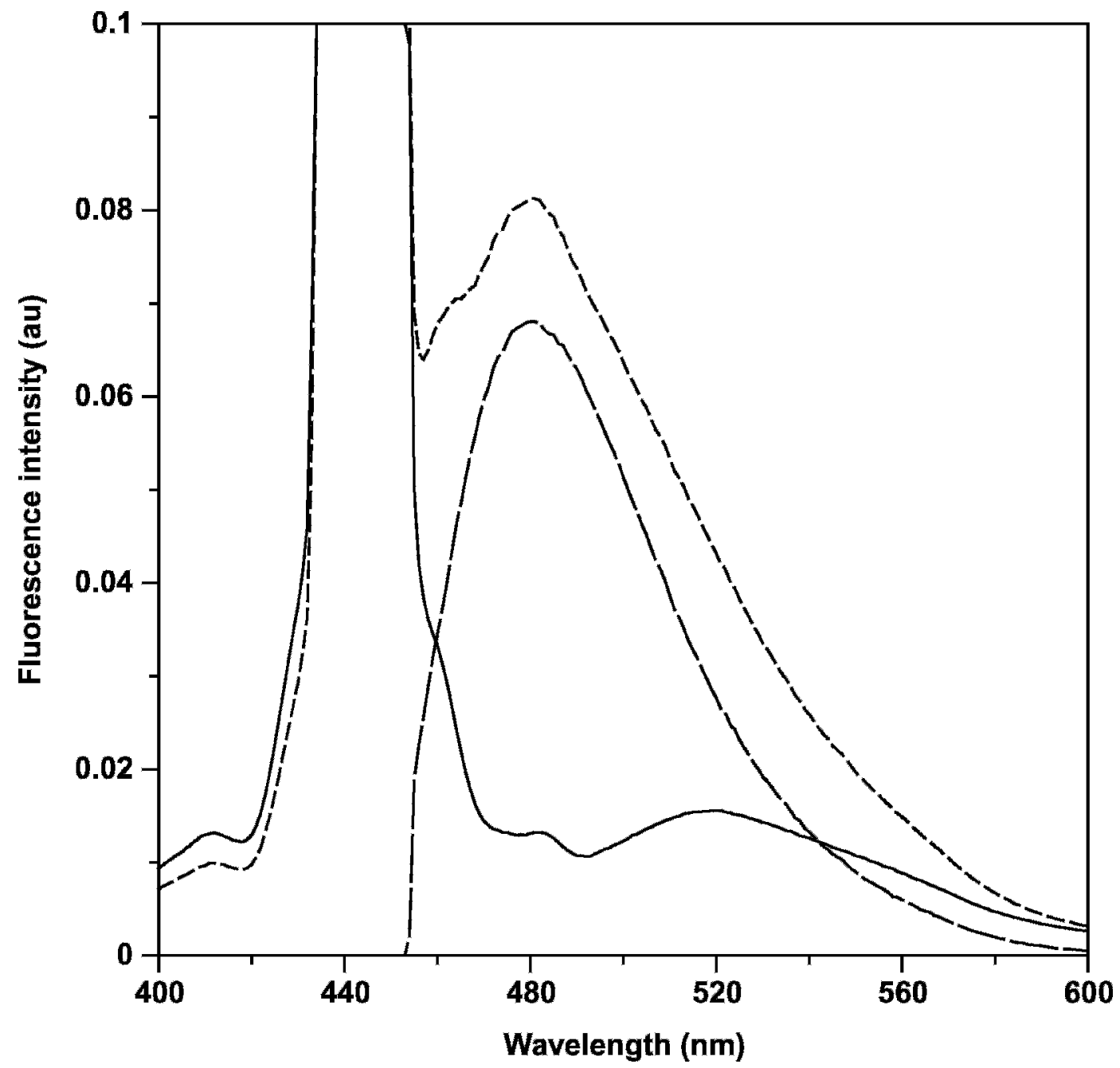

Figure 5. Thioflavin $\mathrm{T}(\mathrm{ThT})$ fluorescence spectra (arbitrary units) for $15 \times$ diluted raw skim milk in a $1.0-\mathrm{cm}^{2}$ cuvette: $-=$ raw milk; - - - = raw milk + ThT; - - = difference curve.

addition, a fluorescence peak similar to that detected with skim milk was observed (Figure 7). As was observed with the CR experiments, it would appear that casein micelles, and not whey proteins, were the source of the skim milk fluorescence. If the raw milk casein was isoelectrically precipitated at a $\mathrm{pH}$ of 4.35 by acidification with $\mathrm{HCl}$, and then resuspended by addition of $\mathrm{NaOH}$ to $\mathrm{pH} 6.8$, after ThT addition and $20 \times$ dilution with 0.1 $M$ HEPES buffer ( $\mathrm{pH}=6.8$ ), a fluorescence peak smaller than that observed with the casein micelles was obtained (Figure 7). This would indicate that fibril structure is reduced but not eliminated when CCP is solublized during isoelectric precipitation. The addition of $25 \mathrm{mM} \mathrm{CaCl} \mathrm{Cl}_{2}$ to this caseinate solution had a positive effect on fluorescent intensity (Figure 7) so some restoration of lost structure is possible.

\section{Detection in Purified Caseins}

Figure 8 shows CR difference curves generated for $0.5 \mathrm{~g} / \mathrm{L}$ solutions of commercially available $\alpha_{\mathrm{S}^{-}}, \beta$-, and $\kappa$-casein preparations in $0.1 M$ HEPES buffer $(\mathrm{pH}=$ 6.8). This protein concentration was chosen because it was similar to that found for the individual proteins in the casein micelle CR experiment in Figure 3. Significant absorption shifts were observed with $\alpha_{\mathrm{S}^{-}}$, and $\kappa$-casein, whereas the effect was minimal with $\beta$-casein. Peaks of the same order of magnitude as observed with diluted micelles were obtained, which provides indirect support for the assertion that caseins caused the spectral shift in Figure 3. Further CR experiments were not conducted because of the inherent insensitivity of this fibril detection technique.

As previously observed by Thorn et al. (2005), ThT exhibited a fluorescent peak at $485 \mathrm{~nm}$ in the presence 


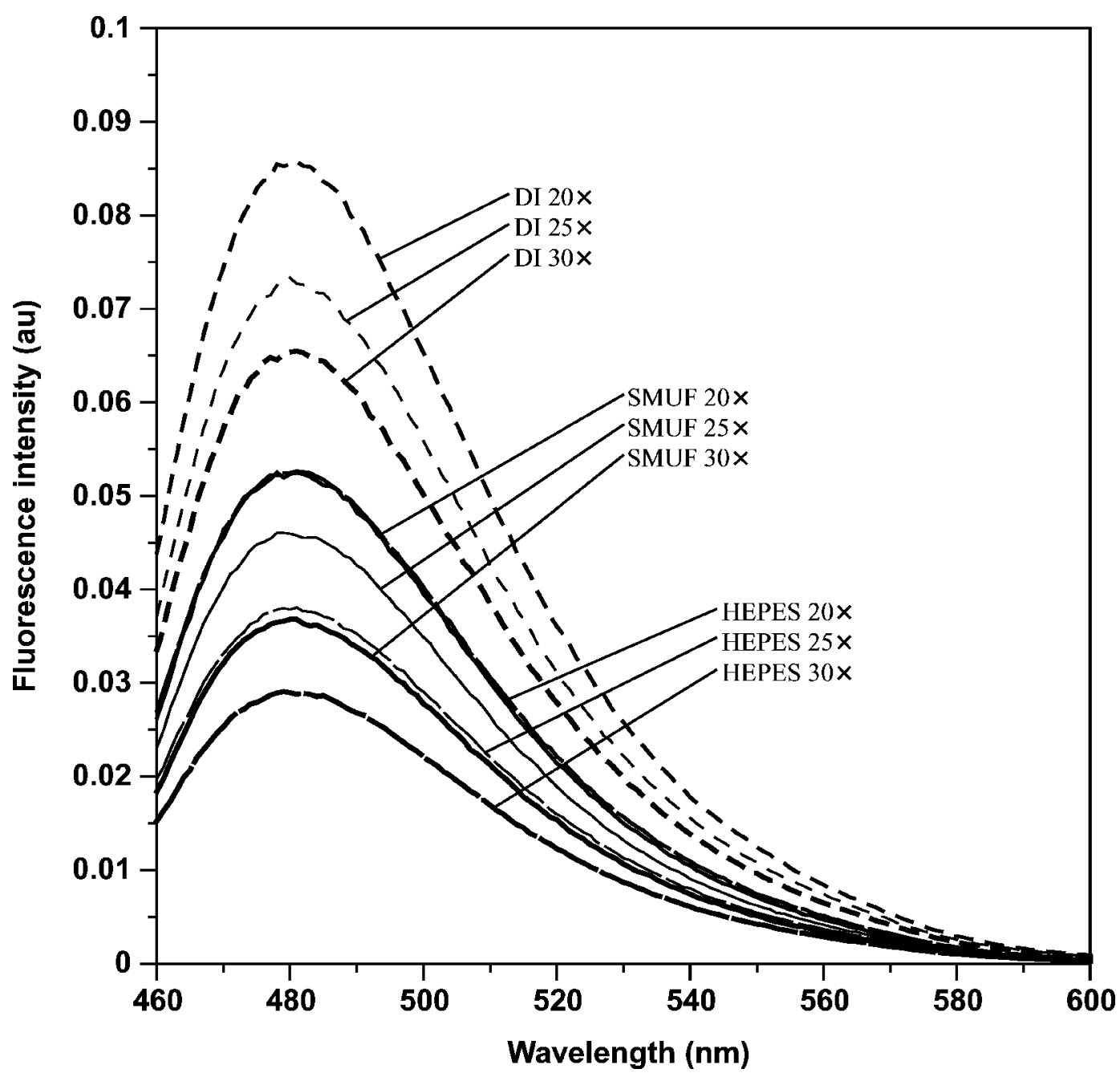

Figure 6. Thioflavin $\mathrm{T}$ (ThT) fluorescence spectra (arbitrary units) for diluted raw skim milk: $\longrightarrow 20 \times ;-25 \times$; $\longrightarrow 30 \times$. Diluents: solid curve $=$ simulated milk ultrafiltrate $(\mathrm{SMUF}) ;$ short dashed curve $=$ deionized water $(\mathrm{DI}) ;$ long dashed curve $=0.05 \mathrm{M}$ HEPES $(\mathrm{pH}=6.8)$.

of $\alpha_{\mathrm{S}^{-}}$and $\kappa$-casein but not $\beta$-casein (Figure 9) when these proteins were dissolved in 0.1 $M$ HEPES buffer $(\mathrm{pH}=6.8)$. The intensity of $\kappa$-casein on a per-gram basis was higher than $\alpha_{\mathrm{S}}$-casein, which follows the same trend as observed with CR (Figure 8). To investigate the possibility that impurities could be responsible for the observed fluorescence, the 3 casein preparations were analyzed by SDS PAGE (Table 1). The major impurity for all 3 preparations was BSA. Solutions $(0.1 \mathrm{~g} / \mathrm{L})$ of this protein, $\alpha$-LA, or $\beta$-LG in $0.1 M$ HEPES buffer $(\mathrm{pH}=6.8)$ were tested and none demonstrated a discernible $485 \mathrm{~nm}$ fluorescent peak in the presence of ThT (results not shown). Thus, impurities did not have a significant effect on the fluorescence of the principal protein in solution. The $\alpha_{\mathrm{S}}$-casein preparation contained both $\alpha_{\mathrm{S}^{-}}$and $\alpha_{\mathrm{S} 2^{-}}$-casein, so it is unclear whether one or both of these proteins were responsible for the observed peak.
In free solution, caseins are known to self-associate into oligomers. With $\alpha_{\mathrm{S} 1}$-casein, the association is progressive and a strong function of $\mathrm{pH}$ and ionic strength, whereas $\beta$ - and $\kappa$-casein form micellar structures with critical micelle concentrations of around $0.5 \mathrm{~g} / \mathrm{L}$. (Swaisgood, 2003). Fluorescence experiments were conducted at concentrations spanning the range at which these structures form (i.e., 0.1, 0.5, and $1.0 \mathrm{~g} / \mathrm{L}$ ) to see if self-association plays a role in fibril formation. Peak heights for $\alpha_{\mathrm{S}^{-}}$and $\kappa$-casein were roughly proportional to protein concentration, indicating that selfassociation was not critical for fluorescent behavior. The $\beta$-casein solutions did not significantly fluoresce at any of the concentrations examined, and cooling these solutions to $5^{\circ} \mathrm{C}$ (conditions under which $\beta$-casein is known to only be in the monomeric form; Kajiwara et al., 1988) did not significantly increase fluorescence. Disulfide cross-links can occur with some 


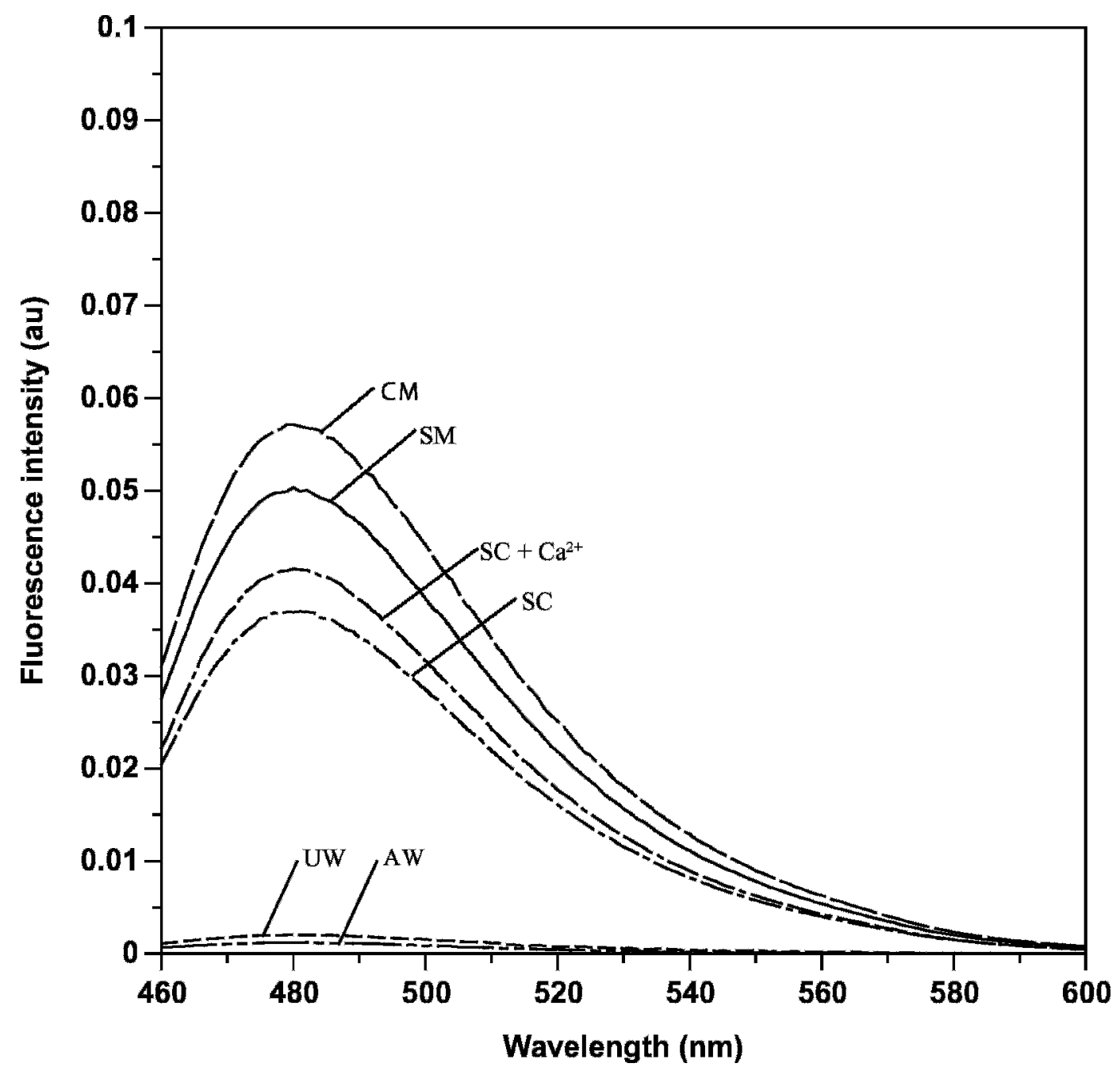

Figure 7. Thioflavin $\mathrm{T}(\mathrm{ThT})$ fluorescence spectra (arbitrary units) for $20 \times$ dilution: — _ skim milk (SM)*; - - ultracentrifugation whey

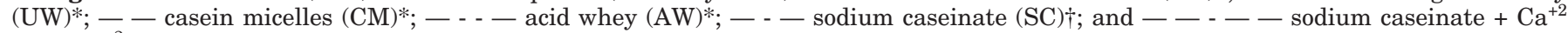
$\left(\mathrm{SC}+\mathrm{Ca}^{2+}\right) \dagger$. Samples were diluted with simulated milk ultrafiltrate $(*)$ or $0.5 \mathrm{M}$ HEPES, $\mathrm{pH}=6.8(\dagger)$.

caseins (particularly $\alpha_{\mathrm{S}^{-}}$and $\kappa$-casein; Swaisgood et al., 1964) but peak height was unaffected by the addition of $2 \%$ mercaptoethanol (results not shown). The addition of $25 \mathrm{mM} \mathrm{CaCl}$ greatly increased solution turbidity and ThT fluorescence in the presence of the very $\mathrm{Ca}^{2+}$-sensitive protein $\alpha_{\mathrm{S}}$-casein, whereas a fluorescence decrease was observed with $\kappa$-casein (Figure $10)$. Even though $\beta$-casein is also $\mathrm{Ca}^{2+}$-sensitive, and the solution was slightly turbid after the addition of 25 $\mathrm{mM} \mathrm{CaCl}$, the presence of this salt had no noticeable effect on ThT fluorescence.

\section{Detection via TEM Analysis}

Imaging of casein micelles is a challenge because the fixation and staining steps can introduce artifacts. Samples for scanning electron microscopy are easy to prepare but the metal that is applied tends to coat the surface, obscuring the fine detail of the micelle structure (McMahon and McManus, 1998). Transmission electron microscopy can provide higher resolution and more sample preparation options. The simplest preparation involves the application of a negative stain followed by air-drying. The drying step can affect sample structure (Talmon, 1983), so cryo-TEM methods have been recommended (McMahon and McManus, 1998). Both air-drying and cryogenic preparation methods were examined but the images obtained with either technique were very similar. Phosphotungstic acid was chosen for the stain because it is known for its consistency and it has a pH optimum of 6.9 (Hayat, 2000 ), which is very close to that of milk. Figure 11a shows a typical image obtained for a casein micelle using the simpler air-drying method. 


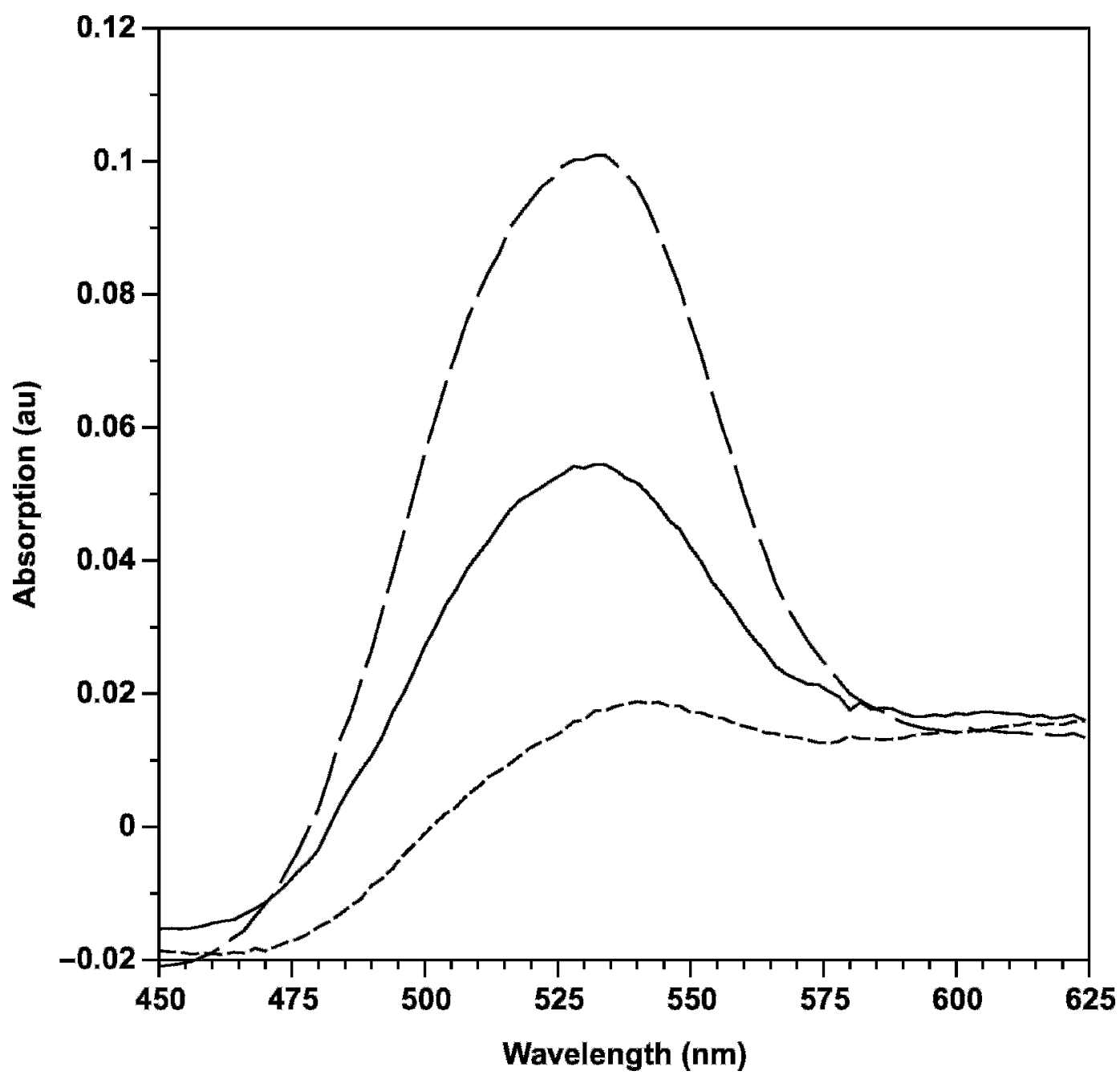

Figure 8. Congo red difference spectra (arbitrary units) for $0.5 \mathrm{~g} / \mathrm{L}$ casein solutions in $0.5 \mathrm{M} \operatorname{HEPES}(\mathrm{pH}=6.8):-=\alpha_{\mathrm{S}}-\mathrm{casein} ;---=$ $\beta$-casein; and $--=\kappa$-casein.

The micelle consisted of an interwoven coral-like network of fine strands. The strands have a diameter of approximately 5 to $10 \mathrm{~nm}$ and are linked together by electron-dense junction points. A similar morphology can be clearly seen in casein micelle images by Waninge et al. (2004) who used a cryo-TEM preparation method. Heertje et al. (1985) also observed what they called thread-like and corpuscular structures in micelles prepared by freeze-fracturing and rotary shadowing. Transmission electron microscopy images of sodium caseinate showed that the proteins still possess some degree of supermacromolecular structure but without the electron-dense junction points (Figure $11 b)$.

\section{DISCUSSION}

As previously observed by Thorn et al. (2005), $\alpha_{\mathrm{S}^{-}}$ and $\kappa$-casein did, but $\beta$-casein did not, interact with
ThT to produce a 485-nm fluorescent peak. The CR absorption shift results followed the same trend. Thus, in free solution, $\alpha_{\mathrm{S}^{-}}$and $\kappa$-casein appear to have fibrillike structures. These structures do not appear to be a result of polymerization of the principal protein or other impurities present in solution. However, one cannot rule out the possibility that some disruption occurred during the protein purification process that created structures prone to fibril formation. Many proteins that are not amyloidogenic in their native form can create fibrils under denaturation conditions (Rochet and Lansbury, 2000). Thus, it was very important to test for the presence of fibril structures in casein micelles under native conditions (i.e., in fresh raw milk handled with as little disruption as possible).

A CR absorption shift was evident with raw skim milk, and fractionation via ultracentrifugation showed that this shift was likely due to casein micelles. How- 


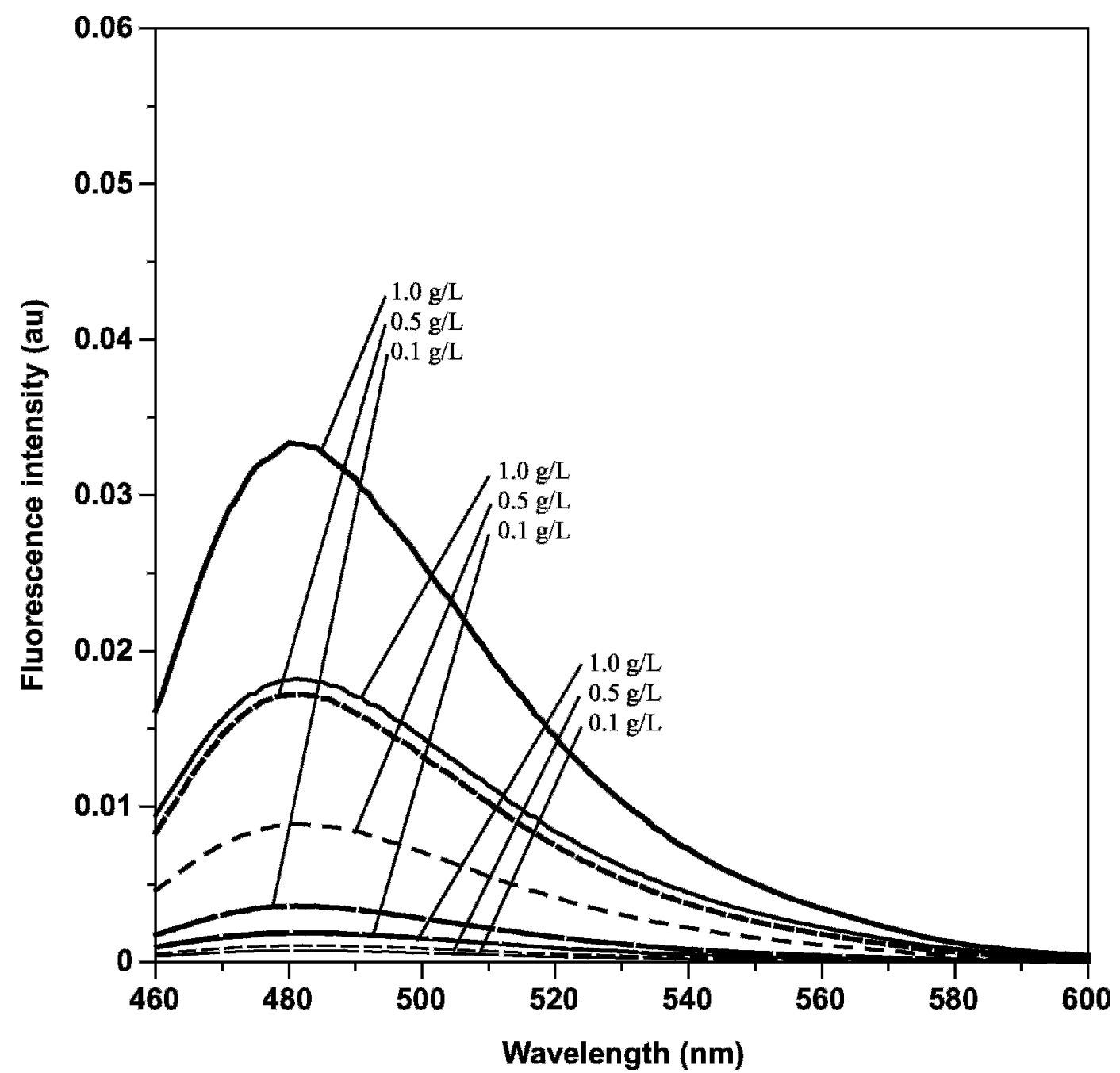

Figure 9. Thioflavin $\mathrm{T}(\mathrm{ThT})$ fluorescence spectra (arbitrary units) for casein solutions in $0.5 \mathrm{MHEPES}(\mathrm{pH}=6.8):-=\alpha_{\mathrm{S}}$-casein; $-=$ $\beta$-casein; $=\kappa$-casein. Concentrations: solid curve $=1.0 \mathrm{~g} / \mathrm{L} ;$ short dashed curve $=0.5 \mathrm{~g} / \mathrm{L} ;$ and long dashed curve $=0.1 \mathrm{~g} / \mathrm{L}$.

ever, the CR method required a large amount of dilution to minimize Rayleigh scattering. Although the nature of the diluting media did not have a large effect on the CR difference peak height, changes in protein solution concentration could potentially alter micelle

Table 1. Analysis of commercial preparations of $\alpha_{\mathrm{s}}-, \beta$-, and $\kappa$-casein by SDS-PAGE (wt\%)

\begin{tabular}{lccc}
\hline & $\alpha_{\mathrm{S}}$-Casein & $\beta$-Casein & $\kappa$-Casein \\
\hline$\alpha_{\mathrm{S} 1}$-Casein & 80.8 & $<0.5$ & 3.6 \\
$\alpha_{\mathrm{S} 2}$-Casein & 7.1 & $<0.5$ & $<0.5$ \\
$\beta$-Casein & 2.1 & 90.6 & $<0.5$ \\
$\kappa$-Casein & 1.2 & $<0.5$ & 83.0 \\
$\gamma$-Casein & $<0.5$ & 1.9 & 2.3 \\
$\alpha$-Lactalbumin & $<0.5$ & 1.3 & 1.0 \\
$\beta$-Lactoglobulin & $<0.5$ & $<0.5$ & 2.0 \\
Bovine serum albumin & 7.8 & 6.2 & 8.0 \\
\hline
\end{tabular}

structure. However, fluorescence analysis with ThT, conducted without any significant dilution of the raw skim milk, once again indicated the presence of fibrillike structures. The ThT method is considered more reliable than the CR method (Khurana et al., 2005); thus, it appears very likely that some naturally occurring protein in raw skim milk is interacting with the ThT to create a fluorescence peak at $485 \mathrm{~nm}$. As was observed with the CR experiments, ultracentrifugation experiments showed that casein micelles appeared to be the species responsible for this peak.

Another indirect indication that caseins were responsible for the absorption shift and fluorescent peak is that, when experiments were conducted with purified $\alpha_{S^{-}}$and $\kappa$-casein at concentrations similar to those present in the raw skim milk micelle experiments, peak heights in both experiments were of the same 


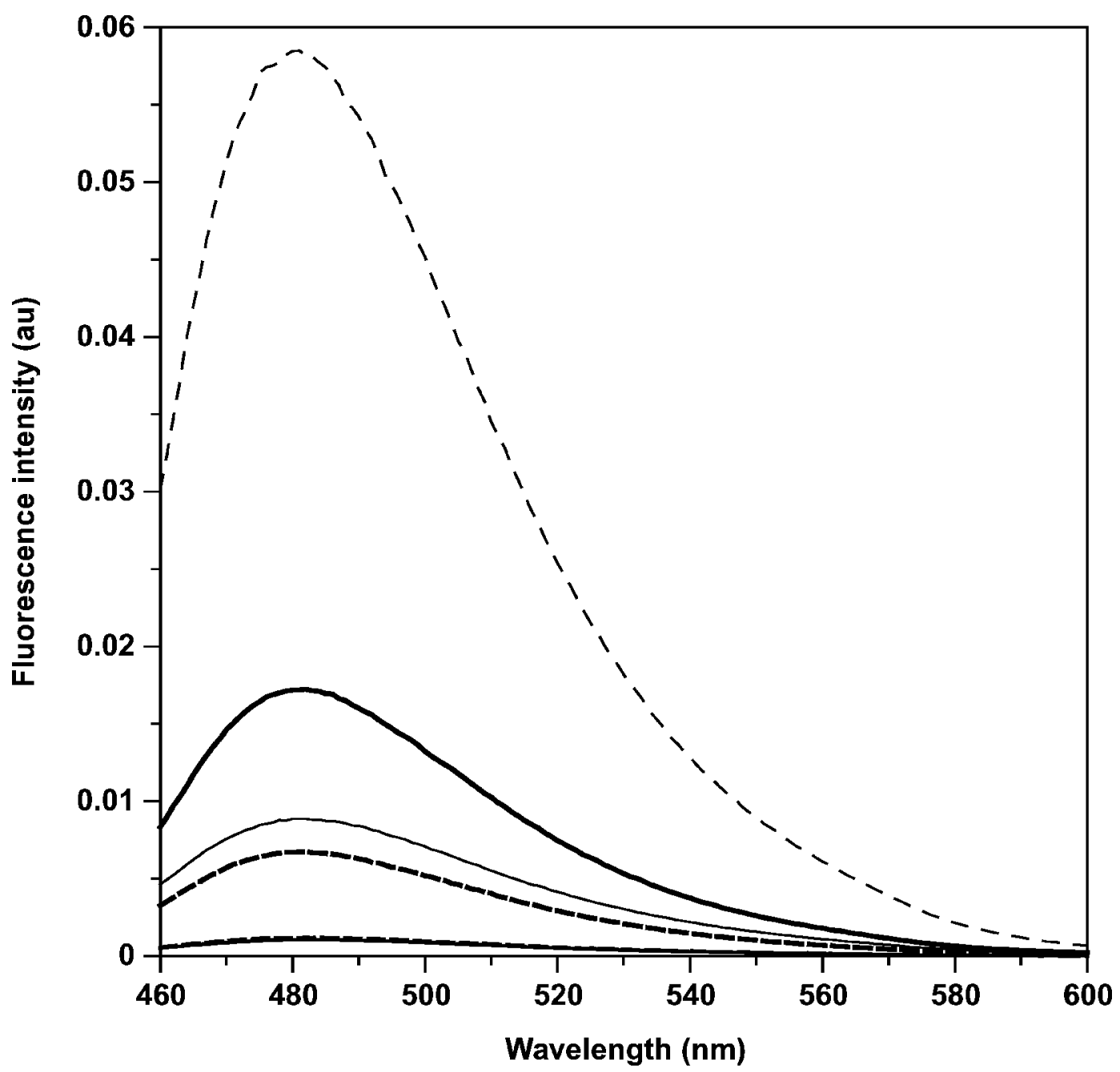

Figure 10. Effect of $25 \mathrm{mM} \mathrm{CaCl}{ }_{2}$ addition on thioflavin $\mathrm{T}$ (ThT) fluorescence spectra (arbitrary units) for casein solutions in $0.5 M$ HEPES $(\mathrm{pH}=6.8)$ : $-=\alpha_{\mathrm{S}^{-}}$casein; $-=\beta$-casein; $=\kappa$-casein. Solid curve $=$ without $\mathrm{Ca}^{2+} ;$ short dashed curve $=$ with $\mathrm{Ca}^{2+}$.

order of magnitude. Computer-based molecular modeling studies indicate that both $\alpha_{\mathrm{S}^{-}}$and $\kappa$-casein have sheet-turn-sheet motifs (Kumosinski et al., 1993; Alaimo et al., 1999)—the primary fibril building blocks. In fact, Farrell et al. (2003) have shown that $\kappa$-casein contains $4 \beta$-sheet structures separated by proline-centered turns and that these groups can interact to form fibril structures. They also obtained a ThT fluorescence peak in the presence of native $\kappa$ casein. However, their computer simulations also suggested that the $\kappa$-casein $\beta$-sheet structures in solution retain an open framework. Consequently, they speculated that the hydrophobic pocket inside the associated $\kappa$-casein aggregate provides the environment that induces probe fluorescence.

The proper interpretation of $\mathrm{CR}$ or ThT results requires an understanding of how the probes specifically interact with fibril structures. The CR absorption site has been characterized (Klunk et al., 1989) but the ThT site is still not well understood (Dzwolak and Pecul, 2005). Nevertheless, because there is very good correlation between the results obtained with both probes, one would suspect that the absorption sites are similar. It is believed that CR is specific to fibril structures because it has the proper length and functional group orientation to form an ionic bridge between 4 superimposed pleated $\beta$-sheets (Klunk et al., 1989).

Simple hydrophobic interactions typically do not induce ThT fluorescence. This probe does not demonstrate a $485 \mathrm{~nm}$ fluorescent peak in the presence of the protein native structure, polymers, or random aggregates; fluorescence is only observed when amyloids are present (LeVine, 1999). Our results show that $\kappa$ - 

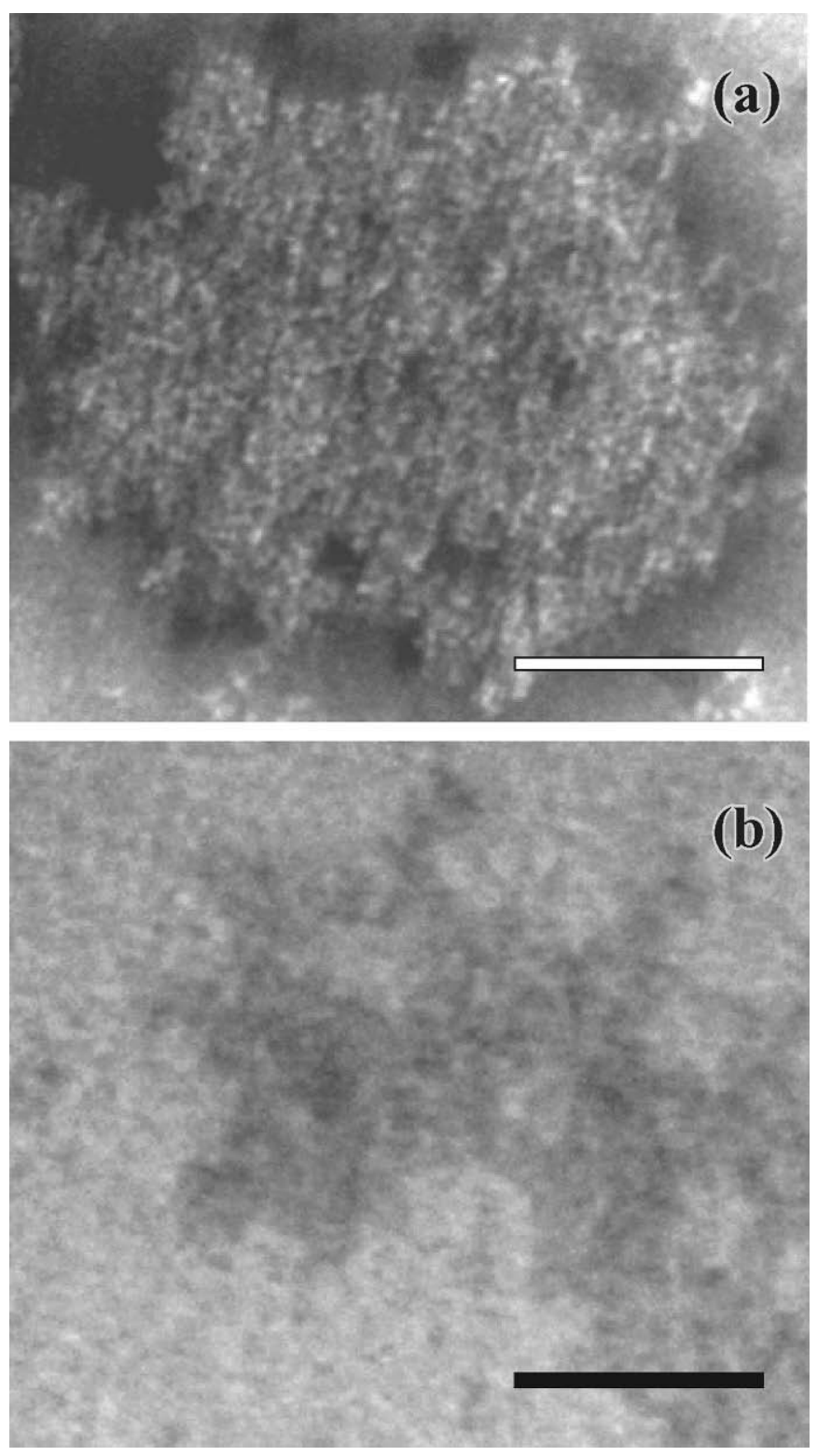

Figure 11. Transmission electron microscopy images of: (a) a casein micelle; (b) sodium caseinate. White bar = $50 \mathrm{~nm}$; black bar = $25 \mathrm{~nm}$.

casein-induced ThT fluorescence was roughly proportional to protein concentration with or without mercaptoethanol addition at concentrations throughout the monomer to polymer transition (Figure 9). Evidently, ThT fluorescence does not require the formation of a hydrophobic aggregate core; therefore, it appears that, in the native form, $\kappa$-casein pleated $\beta$-sheet structures closely interact in a way that is independent of the degree of association.

Farrell et al. (2003) also observed that ThT fluorescence increases when the native $\kappa$-casein is trans- formed to amyloid fibrils and suggested that this was a result of changes in the structure of the absorption site. However, another explanation would simply be that when interprotein $\beta$-sheet structures laminate, new absorption sites are created, thus increasing overall fluorescence. Because fluorescence peak height per gram of protein was relatively constant throughout the association transition for both $\alpha_{\mathrm{S}^{-}}$and $\kappa$-casein, it is unlikely that interprotein interactions within the pure protein associated structures involve pleated $\beta$ sheet lamination.

It is apparent from our initial results that calcium plays an important role in mediating at least some interprotein pleated $\beta$-sheet interactions. Comparing the peaks obtained with casein micelles and sodium caseinate, calcium removal reduced but did not eliminate ThT fluorescence (Figure 7). The observed loss could be partially recovered by adding $25 \mathrm{mM} \mathrm{CaCl} 2$. This phenomenon can be explained by examining the effect of $\mathrm{Ca}^{2+}$ on the pure protein solutions. Calcium induced aggregation of $\alpha_{\mathrm{S}}$-casein led to a 6 -fold increase in ThT fluorescence (Figure 10). Evidently, it would appear that in the presence of calcium, $\alpha_{\mathrm{S}}$-casein self-association is at least partially mediated by interprotein pleated $\beta$-sheet interactions. These same interactions are likely present inside the casein micelle.

Although the analysis of casein micelles with TEM is prone to artifacts, it can be used to provide some indication of the nature of the possible fibril structures present. Because casein micelles have an average diameter of approximately $150 \mathrm{~nm}$, it is highly unlikely that fully formed amyloid structures containing several intertwined fibrils having a length up to $600 \mathrm{~nm}$ are present in these colloidal particles. However, there are several intermediate fibril structures that also interact with $\mathrm{CR}$ and ThT that could be present in casein micelles (Dobson, 2003). Figure 11a indicates the presence of short strands 7 to $10 \mathrm{~nm}$ in diameter, which would be more on the order of protofibrils (Blake and Serpell, 1996). These protofibrils also appear to be conserved in sodium caseinate (Figure 11b), which also interacts with $\mathrm{CR}$ and ThT in a manner that indicates the presence of fibril-like structure. Dense junction zones were present in casein micelles (Figure 11a) but less so in sodium caseinate. $\alpha_{\mathrm{S}^{-}}$Casein is known to interact with calcium, forming 5-nm diameter aggregates (Dosako et al., 1980) that are of comparable size to those observed in Figure 11a. The addition of $\mathrm{Ca}^{2+}$ to $\alpha_{\mathrm{S}}$-casein greatly increased solution turbidity and ThT fluorescence (Figure 10). Therefore, these aggregates could be similar in structure to those created at the onset of amyloid fibril formation (Dobson, 2003).

Because no peak is observed on differential scanning calorimetry thermographs, it was initially speculated 
that caseins were very heat stable (Paulsson and Dejmek, 1990). Circular dichroism analysis (Swaisgood, 2003) has shown that these proteins do possess a significant amount of $\beta$-sheet, $\beta$-turn, and some $\alpha$-helix structure. However, the reliability of the calculated $\alpha$ helix, $\beta$-structure, and $\beta$-turn concentrations is uncertain because globular protein databases were used to determine the appropriate fitted values. Fibrils are very heat stable (Sunde and Blake, 1997) so this could explain why caseins do not display a denaturation endotherm. Because of their high stability, fibrils are generally avoided in in vivo proteins because excessive accumulation of these structures can lead to pathological disease (Sunde and Blake, 1997). As a result, they are not often found in nature: the egg stalk of Chrysopa flava and a number of insect silks are rare examples (Sunde and Blake, 1997). On the other hand, fibrillike structures in mammalian milk could have several advantages: Protein destabilization and aggregation inside the cow's udder would have serious consequences to the animal's health and milk production. Thus, maintaining a stable casein structure until it reaches the calf's stomach is crucial. Furthermore, fibrils are often associated with metal ions (Sunde and Blake, 1997). The presence of these structures could therefore increase micellar chelation capacity, leading to higher levels of CCP solubilization.

\section{ACKNOWLEDGMENTS}

I would like to thank A. Shum for her help with the various analyses. This work was supported by a grant from the National Science and Engineering Research Council of Canada.

\section{REFERENCES}

Alaimo, M. H., H. M. Farrell, Jr., and M. W. Germann. 1999. Conformational analysis of the hydrophobic peptide $\alpha_{\mathrm{S1}}$-casein (f 136196). Biochim. Biophys. Acta 1431:410-420.

Bellare, J. R., H. T. Davis, L. E. Scriven, and Y. Talmon. 1988. Controlled environment vitrification system: An improved sample preparation technique. J. Electron Microsc. Tech. 10:87-111.

Benzinger, T. L., D. M. Gregory, T. S. Burkoth, H. Miller-Auer, D. G. Lynn, R. E. Botto, and S. C. Meredith. 1998. Propagating structure of Alzheimer's $\beta$-amyloid(10-35) is parallel $\beta$-sheet with residues in exact register. Proc. Natl. Acad. Sci. USA 95:13407-13412.

Blake, C., and L. Serpell. 1996. Synchrotron x-ray studies suggest that the core of the transthyretin amyloid fibril is a continuous $\beta$-sheet helix. Structure 4:989-998.

Boulet, M., A. Yang, and R. R. Riel. 1970. Examination of the mineral composition of the micelle of milk by gel filtration. Can. J. Biochem. 48:816-822.

Carrotta, R., R. Bauer, R. Waninge and C. Rischel. 2001. Conformational characterization of oligomeric intermediates and aggregates in $\beta$-lactoglobulin heat aggregation. Protein Sci. 10:1312-1318.

de Kruif, C. G., and C. Holt. 2003. Casein micelle structure, functions and interactions. Pages 233-276 in Advanced Dairy Chemistry,
Volume 1: Proteins. 3rd ed. P. F. Fox and P. L. H. McSweeney, ed. Kluwer, New York, NY.

Dobson, C. M. 2003. Protein folding and misfolding. Nature 426:884-890.

Dosako, S., T. Kimura, S. Taneya, T. Sone, S. Kaminogawa, and K. Yamauchi. 1980. Polymerization of $\alpha_{\mathrm{S} 1}$-casein by calcium ions. Agric. Biol. Chem. 44:2443-2448.

Dzwolak, W., and M. Pecul. 2005. Chiral bias of amyloid fibrils revealed by the twisted conformation of Thioflavin T: An induced circular dichroism/DFT study. FEBS Lett. 579:6601-6603.

Farrell, H. M., Jr. 1988. Physical equilibria: Proteins. Pages 461510 in Fundamentals of Dairy Chemistry. 3rd ed. N. Wong, ed. Van Nostrand, New York, NY.

Farrell, H. M., Jr., P. H. Cooke, E. D. Wickham, E. G. Piotrowski, and P. D. Hoagland. 2003. Environmental influences on bovine $\kappa$-casein: Reduction and conversion to fibrillar (amyloid) structures. J. Protein Chem. 22:259-273.

Fink, A. L. 1998. Protein aggregation: Folding aggregates, inclusion bodies and amyloids. Fold. Des. 3:R9-R23.

Griffin, M. C. A., and G. C. K. Roberts. 1985. A ${ }^{1}$ H-n.m.r. study of casein micelles. Biochem. J. 228:273-276.

Hayat, M. A. 2000. Principles and techniques of electron microscopy: Biological applications. Cambridge University Press, Cambridge, UK.

Heertje, I., J. Visser, and P. Smits. 1985. Structure formation in acid milk gels. Food Microstruct. 4:267-277.

Holt, C. 1992. Structure and stability of bovine casein micelles. Adv. Protein Chem. 43:63-151.

Holt, C., and L. Sawyer. 1993. Caseins as rheomorphic proteins: Interpretation of the primary and secondary structures of the $\alpha$ s1-, $\beta$ - and $\kappa$-caseins. J. Chem. Soc. Faraday Trans. 89:2683-2692.

Jenness, R., and J. Koops. 1962. Preparation and properties of a salt solution which simulates milk ultrafiltrate. Neth. Milk Dairy J. 16:153-164

Kajiwara, K., R. Niki, H. Urakawa, Y. Hiragi, N. Donkai, and M. Nagura. 1988. Micellar structure of $\beta$-casein observed by smallangle x-ray scattering. Biochim. Biophys. Acta 955:128-134.

Kelly, J. W. 1996. Alternative conformations of amyloidogenic proteins govern their behaviour. Curr. Opin. Struct. Biol. 6:11-17.

Khurana, R., C. Coleman, C. Ionescu-Zanetti, S. A. Carter, V. Krishna, R. K. Grover, R. Roy, and S. Singh. 2005. Mechanism of thioflavin $\mathrm{T}$ binding to amyloid fibrils. J. Struct. Biol. 151:229-238.

Klunk, W. E., R. F. Jacob, and R. P. Mason. 1999. Quantifying amyloid by Congo red spectral shift assay. Meth. Enzymol. 309:285-305.

Klunk, W. E., J. W. Pettegrew, and D. J. Abraham. 1989. Two simple methods for quantifying low-affinity dye-substrate binding. J. Histochem. Cytochem. 37:1293-1297.

Kumosinki, T. F., E. M. Brown, and H. M. Farrell, Jr. 1993. Three dimensional molecular modeling of bovine caseins: A refined energy-minimized $\kappa$-casein structure. J. Dairy Sci. 76:25072520 .

LeVine, H., III. 1999. Quantification of $\beta$-sheet amyloid fibril structures with thioflavin-T. Meth. Enzymol. 309:274-284.

Li, X., B. Chance, and A. G. Yodh. 1998. Fluorescent heterogeneities in turbid media: Limits of detection, characterization and comparison with absorption. Appl. Opt. 37:6833-6844.

McMahon, D. J., and W. R. McManus. 1998. Rethinking casein micelle structure using electron microscopy. J. Dairy Sci. 81:2985-2993.

Nelson, R., and D. Eisenberg. 2006. Recent atomic models for amyloid fibril structure. Curr. Opin. Struct. Biol. 16:260-265.

Paulsson, M., and P. Dejmek. 1990. Thermal denaturation of whey proteins in mixtures with caseins studied by differential scanning calorimetry. J. Dairy Sci. 73:590-600.

Price, J. M., M. Kailhara, and H. K. Howerton. 1962. Influence of scattering on fluorescence spectra of dilute solutions obtained with the Aminco-Bowman spectrophotofluorometer. Appl. Opt. 1:521-533.

Rochet, J.-C., and P. T. Lansbury, Jr. 2000. Amyloid fibrillogenesis: Themes and variations. Curr. Opin. Struct. Biol. 10:60-68. 
Rollema, H. S. 1992. Casein association and micelle formation. Pages 111-140 in Advanced Dairy Chemistry Volume 1: Proteins. 2nd ed. P. F. Fox ed. Elvsevier, Barking, UK.

Sunde, M., and C. Blake. 1997. The structure of amyloid fibrils by electron microscopy and x-ray diffraction. Adv. Protein Chem. 50:123-159.

Swaisgood, H. E. 2003. Chemistry of caseins. Pages 139-202 in Advanced Dairy Chemistry Volume 1: Proteins. 3rd ed. P. F. Fox and P. L. H. McSweeney, ed. Kluwer, New York, NY.

Swaisgood, H. E., J. R. Brunner, and H. A. Lillevik. 1964. Physical parameters of $\kappa$-casein from cow's milk. Biochemistry 3: $1616-1623$.
Talmon, Y. 1983. Staining and drying-induced artefacts in electron microscopy of surfactant dispersions. J. Colloid Interf. Sci. 93:366-382.

Thorn, D. C., S. Meechan, M. Sunde, A. Rekas, S. L. Gras, C. E. McPhee, C. M. Dobson, M. R. Wilson, and J. A. Carver. 2005. Amyloid fibril formation by bovine milk $\kappa$-casein and its inhibition by the molecular chaperones $\alpha \mathrm{S}$ - and $\beta$-casein. Biochemistry 44:17027-17036.

Waninge, R., E. Kalda, M. Paulsson, T. Nylander, and B. Bergenståhl. 2004. Cryo-TEM of isolated milk fat globule membrane structures in cream. Phys. Chem. Chem. Phys. 6:1518-1523. 